\title{
Migraines and CGRP Monoclonal Antibodies: A Review of Cardiovascular Side Effects and Safety Profile
}

\author{
Kimberly Boldig, $M^{M S^{1 *}}$ and Nitin Butala, $M D^{2}$ \\ ${ }^{1}$ Medical Student, Lake Erie College of Osteopathic Medicine, Bradenton, USA \\ ${ }^{2}$ Department of Neurology, Baptist Medical Center, Jacksonville, USA
}

*Corresponding author: Kimberly Boldig, Medical Student, Lake Erie College of Osteopathic Medicine, 5000 Lakewood Ranch Blvd, Bradenton, FL 34211, USA, Tel: 414-791-9420

\begin{abstract}
Migraine headaches are a common complaint described by patients and few medications have been designed solely for their treatment. Current knowledge of migraine pathogenesis relates to various neuropeptides, including calcitonin gene related peptide (CGRP), acting on blood vessels within the brain, causing vasodilation. Sensory fibers detect this change and perceive it as pain. This understanding has led to the development of CGRP monoclonal antibodies as a possible migraine treatment.

This class of migraine medication causes concern for possible cardiovascular side effects. Blocking CGRP and the vasodilatory process of migraines may pose a risk for exacerbating cardiovascular disease. CGRP has also demonstrated protective effects on the cardiovascular system by preventing against heart failure, deleterious cardiac remodeling, hypertension, and cell death. Additionally, patients with migraines are also believed to be at greater baseline risk for cardiovascular and cerebrovascular disease. Assessment of a cardiovascular risk profile is essential for the continued use of this medication class.

Various trials within phase II or III of study were analyzed for the risk profiles of CGRP monoclonal antibodies. At this time, no serious cardiovascular adverse effects have been found. The CGRP monoclonal antibodies did not increase rates of cardiovascular adverse events, when compared to placebo. The CGRP monoclonal antibodies were shown to be safe in patients with previous cardiovascular risk as well as those stressed to provoke an adverse cardiovascular event. Many of the phase II and phase III trials had significant female participation, representing a safe cardiovascular profile for those most commonly affected with migraines. This demonstrated that the medication class does not increase risk of cardiovascular side effects in its users.
\end{abstract}

\section{Keywords}

Migraine, Calcitonin gene related peptide (CGRP), Monoclonal antibody, Headache, Cardiovascular

\section{Introduction}

The pathogenesis of migraines remains an area of significant study today. Migraines are hypothesized to involve the trigeminal nerve and innervation of cranial vessels. Studies have demonstrated inflammatory particles likely trigger this cascade. This inflammation stimulates the neurons to depolarize and release calcitonin gene-related peptide (CGRP) [1]. CGRP then causes increased perfusion through cerebral vessels [2]. Dilation of these cerebral vessels stimulates sensory fibers of the trigeminal nerve, which is relayed to the brainstem as pain. The brain then amplifies the release of CGRP into cranial vessels, causing more vasodilation, inflammation, and leakage of vessels [1]. Further research has found that CGRP signaling may specifically occur through $C$-fibers and $A \delta$-fibers in the trigeminal ganglion. With the use of CASPR, a study has shown CGRP receptors are located at nodes of Ranvier in $A \delta$-fibers, while CGRP release occurs from C-fibers [3]. Blocking the effect of CGRP in cranial vessels was the proposed mechanism of calcitonin gene-related peptide monoclonal antibody for migraine treatment. Numerous studies have shown CGRP monoclonal antibodies to be an efficacious medication class [4-10]. Knowing the efficacy of the CGRP monoclonal antibodies, this review focuses on cardiovascular adverse events and possible safety profile expected for women.

Citation: Boldig K, Butala N (2020) Migraines and CGRP Monoclonal Antibodies: A Review of Cardiovascular Side Effects and Safety Profile. Int J Neurol Neurother 7:101. doi.org/10.23937/23783001/1410101

Accepted: July 29, 2020: Published: July 31, 2020

Copyright: (C) 2020 Boldig K, et al. This is an open-access article distributed under the terms of the Creative Commons Attribution License, which permits unrestricted use, distribution, and reproduction in any medium, provided the original author and source are credited. 
Until recently, migraines have been treated with antihypertensive drugs, antidepressants, and antiepileptic medications [4]. These medications are associated with numerous side effects. Currently, one of the most efficacious treatments are triptans. Triptans act as agonists of serotonin receptors 5-HT1B and 5-HT1D and cause vasoconstriction of blood vessels [11]. This mechanism of vasoconstriction helps alleviate symptoms of a migraine and consequentially may trigger ischemic cardiac events. Therefore, many migraine medications present with cardiovascular side effects.

The importance of finding a safer and more effective migraine treatment led to the development of CGRP antagonists. Gepants were developed with the intention to inhibit one of the primary mechanisms behind the pathogenesis of migraines, CGRP. Although studies were initially encouraging, gepants, such as telcagepant, had low bioavailability and caused elevated transaminases. Research has changed focus to blocking CGRP ligand, or its receptor, with a monoclonal antibody [4].

Although CGRP antagonists are associated with significant side effects, the effects on the cardiovascular system have remained benign. Various studies have shown that antagonizing CGRP does not worsen myocardial ischemia, exacerbate stable angina, or cause other cardiovascular side effects [12-14]. An animal model of CGRP antagonism demonstrated no worsening of myocardial ischemia, following a decrease in coronary blood flow [12]. During treadmill exercise in patients with stable angina, CGRP antagonism caused no change in total exercise time, ST- segment depression, time to angina, or change in blood pressure [13]. Due to limited research on CGRP monoclonal antibodies, the lack of cardiovascular side effects associated with CGRP antagonists may represent promising safety outcomes associated with blockade of CGRP.

Two isoforms of CGRP allow for the efficacy of this class medication and may explain possible side effects. The first isoform is $\alpha$-CGRP, which is most active in sensory neurons in the dorsal root ganglia. The second isoform, $\beta$-CGRP, can be found in the enteric nervous system. This is visualized in Figure 1 [4]. The efficacy and safety profile can be explained through the action of $\alpha$-CGRP at the target organ. $\alpha$-CGRP binds the CLR/ RAMP1 receptor, acting on a G-protein Gas cascade and $\mathrm{G} \alpha \mathrm{q} / 11$ pathway. The impact of binding these receptors causes relaxation of vascular smooth muscle, vasodilation, cardiac contraction, and synaptic plasticity. The isoforms and their actions at various organ systems are explained in Figure 2 [15]. The vasodilation caused by $\alpha$-CGRP is profound. In 1985, $\alpha$-CGRP was found to be the most potent vasodilator in the human body [16].

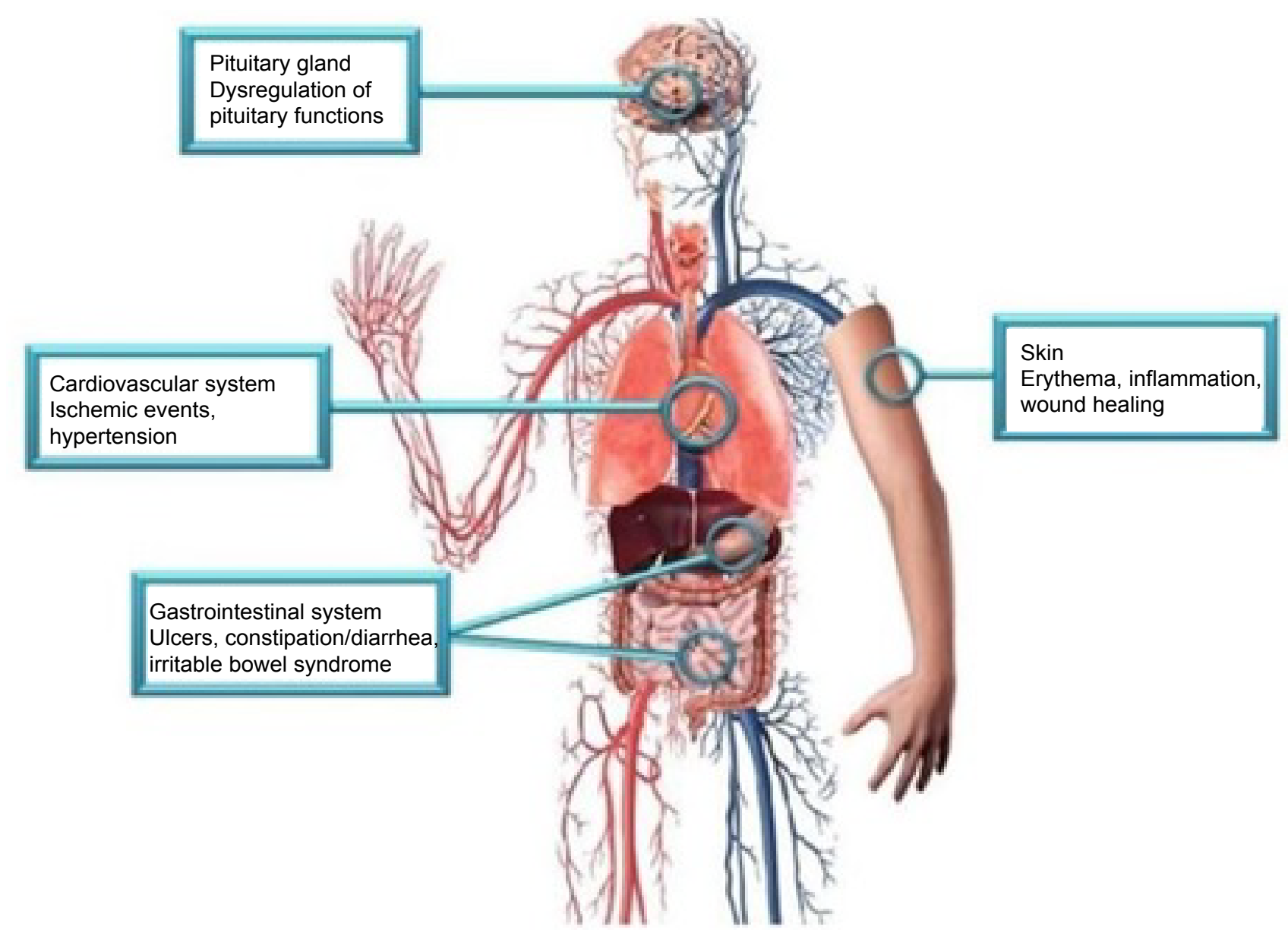

Figure 1: Side effects associated with CGRP blockade may be explained by the action of CGRP in the pituitary gland, cardiovascular system, gastrointestinal system, and skin [4]. 


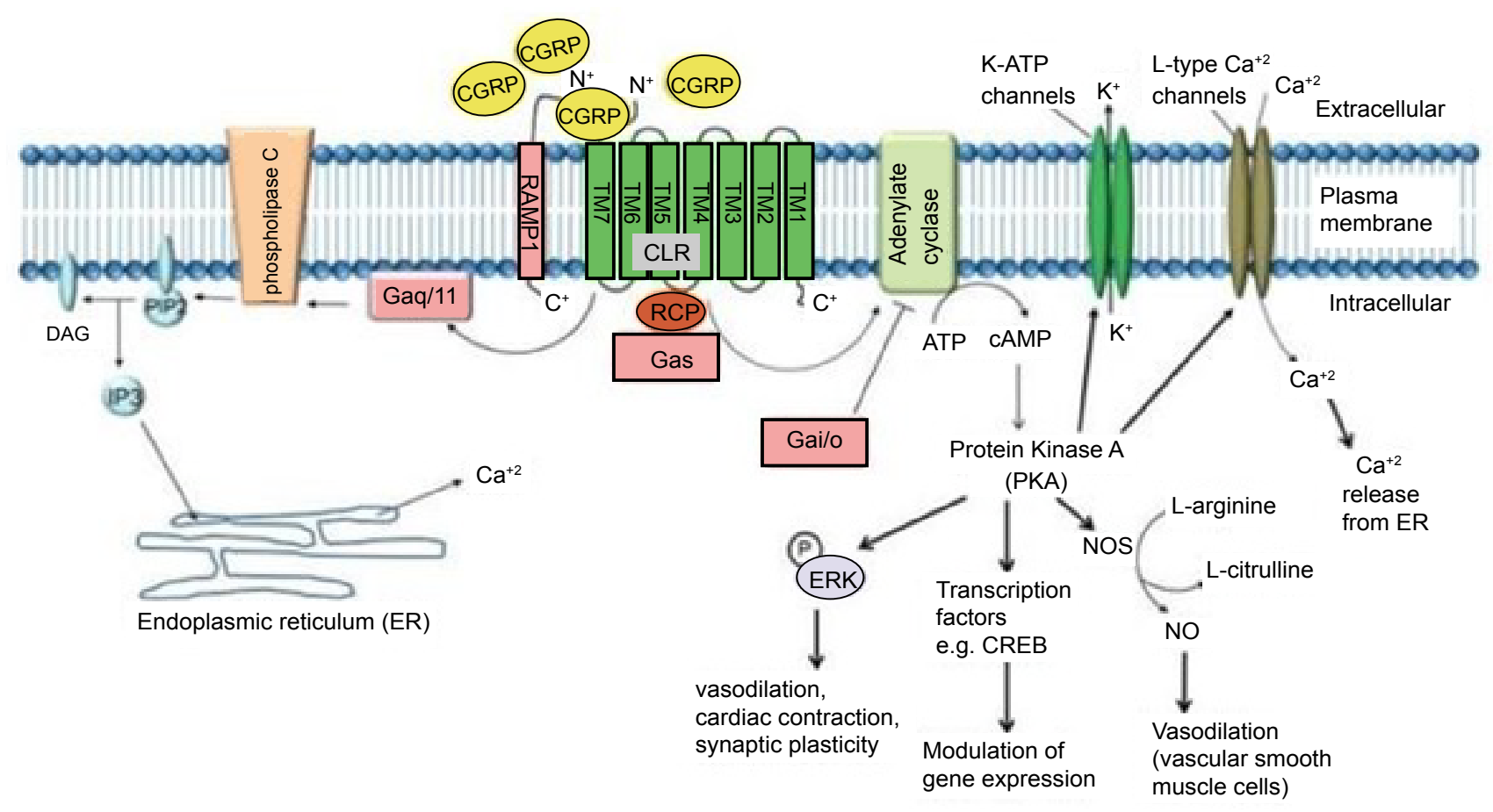

Figure 2: As a Gas receptor, the binding of $\alpha$-CGRP increases cAMP and protein kinase A levels. CGRP can also increase intracellular $\mathrm{Ca}^{+2}$ concentrations by acting through a Gaq/11 pathway [15].

The vasodilatory effects of CGRP are believed to be protective to the brain and heart in light of ischemic events.

The relationship between CGRP blockade and cardiovascular risk may be explained through various molecular pathways. Specifically, this review identifies how CGRP protects against heart failure, ischemic heart disease, and hypertension. Numerous studies discussed below have been reviewed with this understanding in mind, to determine if adverse events frequently occurred.

Along with the vasodilatory effect, $\alpha$-CGRP has been found to prevent cardiac myocyte apoptotic cell death and increase survival in heart failure. Under cellular stress, CGRP leads to decreased cell death through mechanisms such as increasing $\mathrm{Bcl}-2$ and decreasing Bax expression, decreasing oxidative stress, and increasing nitric oxide production [17-19]. A comparison of heart failure in wild type and knock out CGRP mice found that WT mice had a greater survival rate at 28 days. The KO mice had increased incidence of deleterious cardiac remodeling presenting as left ventricular hypertrophy, cardiac fibrosis, apoptosis, necrosis, inflammation, and reduced angiogenesis [20]. CGRP protects against heart failure by blocking cell death and preventing adverse changes within the heart.

Similarly, there may be concern when using CGRP monoclonal antibodies in patients at risk for ischemic cardiac events [15]. Previous studies have demonstrated that CGRP prevented cellular death in mice exposed to 30 minutes of ischemia followed by 30 minutes of reperfusion. In the study, $\alpha$-CGRP knockout mice had a reduction in heart function following the ischemic reperfusion insult. This was measured with creatine kinase, a marker of cellular death. At five, 15, and 30 minutes, the level of creatine kinase was markedly elevated in CGRP knockout mice when compared to wild type mice. Malonaldehyde (MDA) was used in the study to measure oxidative stress. Initially, both types of mice, KO and WT, had the same amount of MDA. After the ischemic refusion insult, the levels of MDA were significantly higher in CGRP knockout mice. The study concludes that CGRP helped to prevent oxidative stress and cellular death of the heart following ischemic reperfusion injury [21]. Based on this knowledge, patients with coronary artery disease are at high risk of adverse events when CGRP is blocked.

Studies have also demonstrated a connection between CGRP and hypertension. Hypertensive rats have been found to have decreased levels of CGRP. This suggests that higher levels of CGRP cause vasodilation, allowing for a decrease in blood pressure [22]. Blood pressure was compared in $\alpha$-CGRP knockout mice and wild type mice. The knockout mice showed elevated systolic blood pressure and mean arterial pressure when compared to wild type mice [23]. $\alpha$-CGRP may also impact hormonal cascades within the body that are important regulators of blood pressure. It is well known that the renin-angiotensin-aldosterone system plays a significant role in hypertension. $\alpha$-CGRP decreases the ability of angiotensin II to increase blood pressure and cause vascular remodeling and oxidative stress [24]. CGRP has been shown to provide various protective effects in the cardiovascular system $[15,24]$. Knowing this, changes in vital signs reported during phase II and III trials will be a valuable measurement of assess how CGRP blockade 

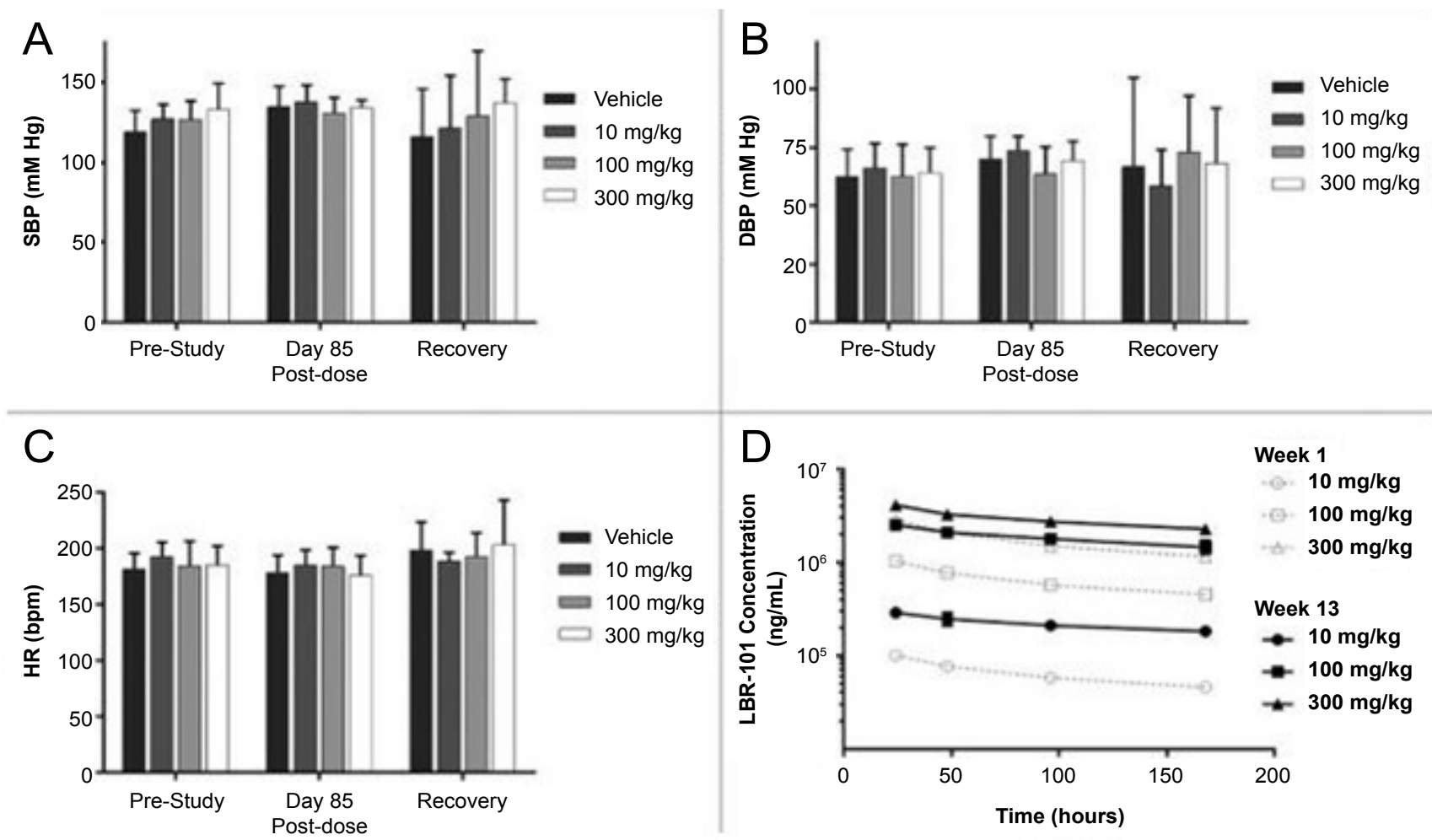

Figure 3: Data was collected prior to the first fremanezumab dose, at day 85 of dosing, and one week after dosing. Data collected during fremanezumab treatment demonstrated no significant difference in systolic blood pressure $(A)$, diastolic blood pressure (B), and heart rate (C). Plasma concentrations were measured to assess accumulation of the drug with repeated dosing [27].
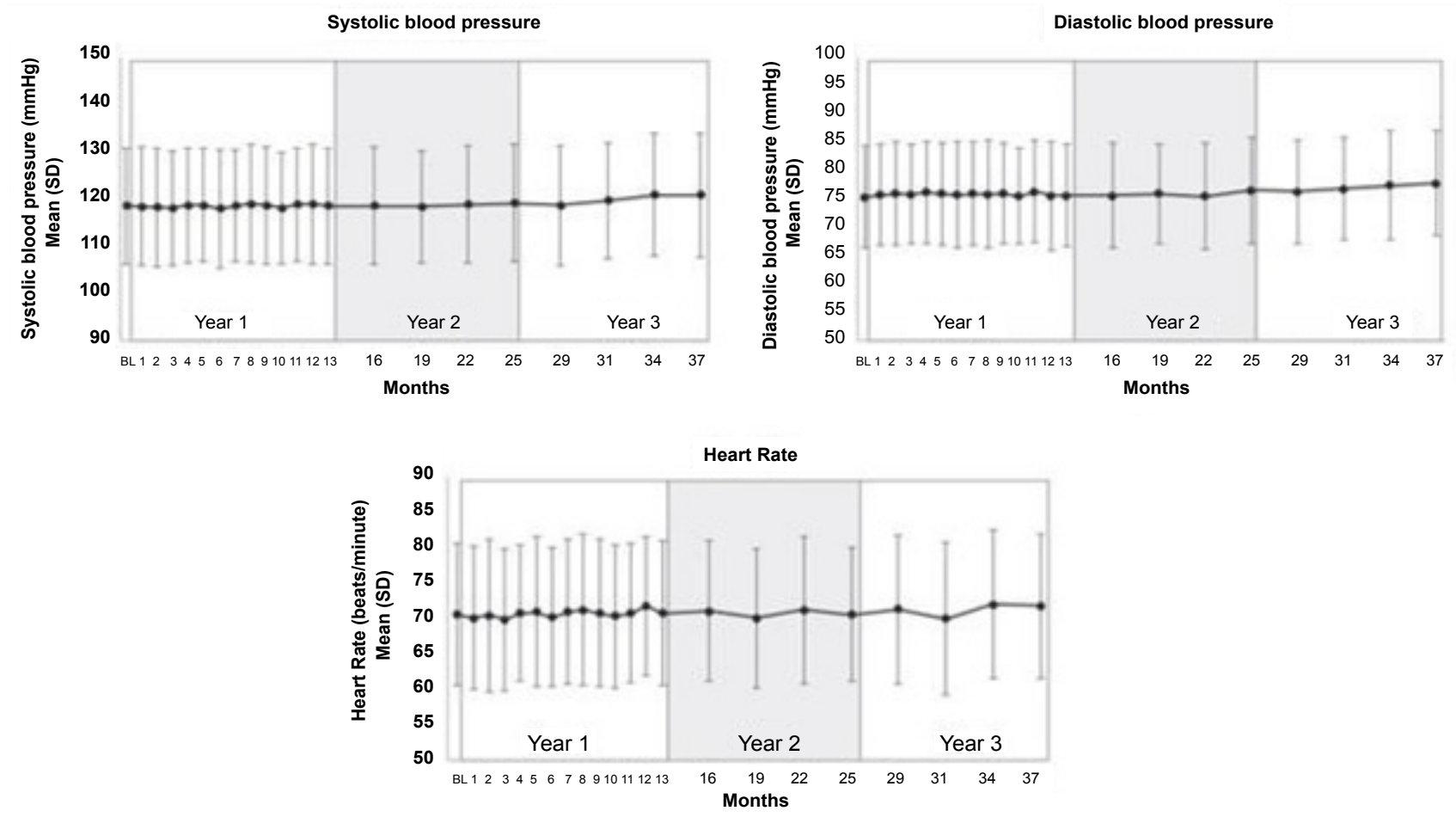

Figure 4: No significant changes in systolic blood pressure, diastolic blood pressure, and heart rate were found during 3.3 years of follow-up [30].

affects the cardiovascular system.

The potential for this medication class to provoke an adverse cardiovascular event causes increased concern because the migraine patient population is already at higher baseline risk. Evidence supports a correlation between migraines and higher cardiovascular and cerebrovascular events [25]. A meta-analysis has shown patients with migraines are at higher risk of stroke and myocardial infarction, when compared to patients with- 
out migraines [26]. Phase II and III trials of CGRP monoclonal antibodies will provide an understanding of how patients with migraines are affected.

Various studies of CGRP monoclonal antibodies have assessed the safety profile of the medication class. Consistency in vital signs was found throughout the studies, as visualized in Figure 3 and Figure 4 [27-32]. Studies of patients with preexisting cardiovascular risk factors have also shown promise. No difference in adverse events were found between the drug treatment group and the placebo group [33]. Figure 5 and Figure 6 demonstrate no differences in cardiovascular measurements were found in patients with angina [29]. Common cardiovascular side effects that have been reported have been hypertension, tachycardia, palpitations, and increased heart rate [34]. These side effects were often explained by events independent from drug administration and

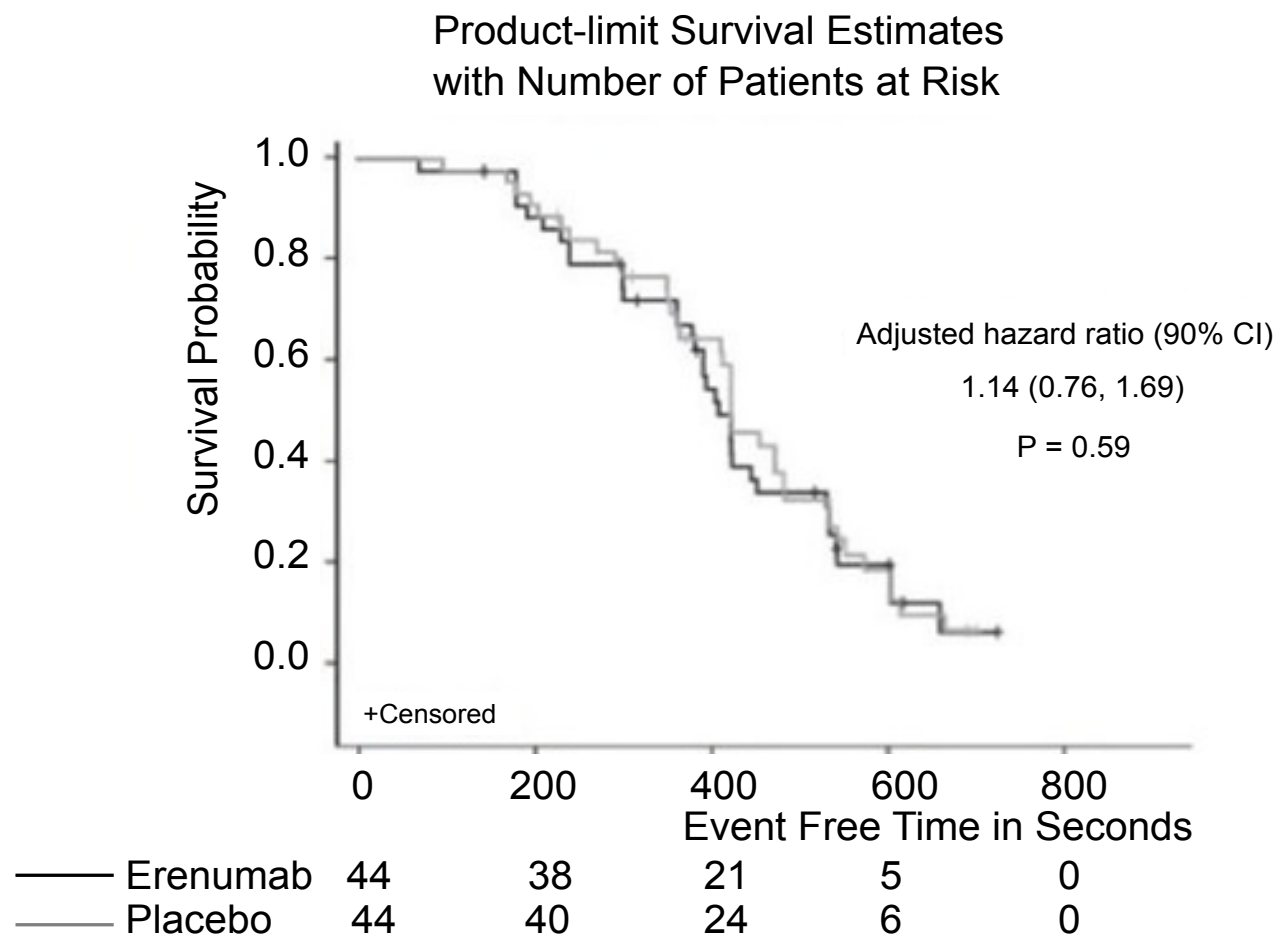

Figure 5: Patients with chronic stable angina were treated with a monoclonal antibody and were assessed for cardiovascular changes during treadmill testing. There was also no difference in time to $>1 \mathrm{~mm}$ ST-segment depression [29].

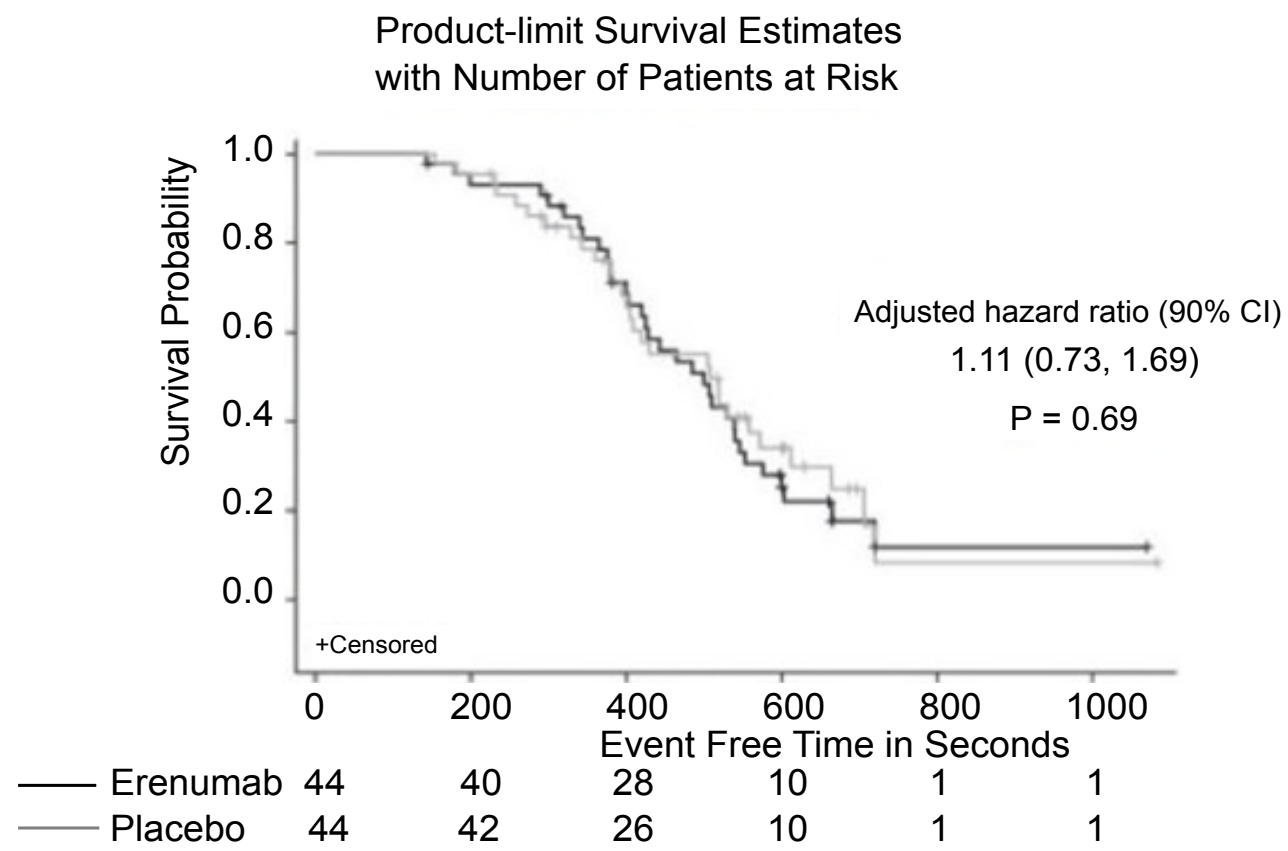

Figure 6: Patients with chronic stable angina also demonstrated no difference in time to exercise-induced angina, when comparing erenumab treatment and placebo [29]. 


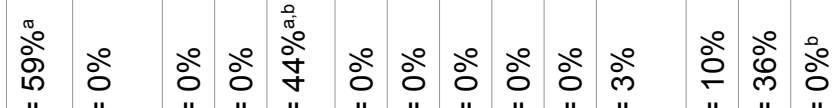

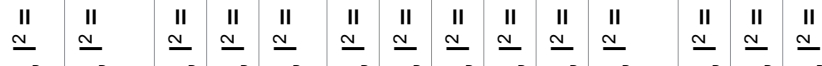

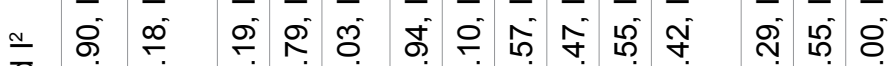

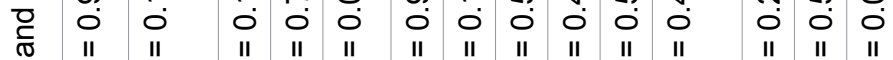

$\begin{array}{llllllllllllllll}0 & 0 & 0 & 0 & 0 & 0 & 0 & 0 & 0 & 0 & 0 & 0 & 0 & 0 & 0\end{array}$

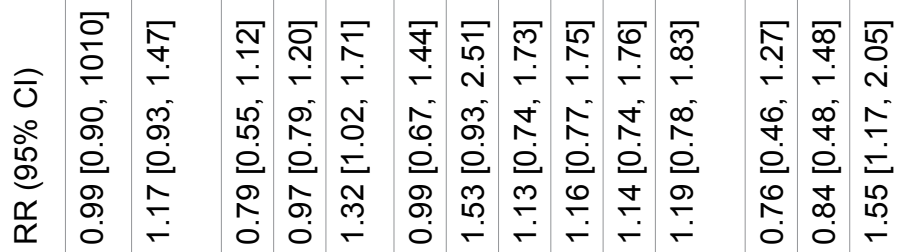

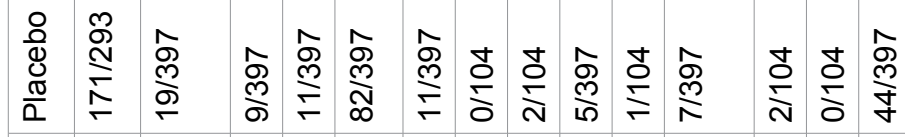

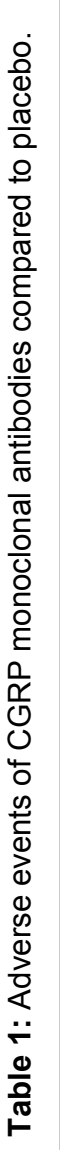

$\frac{\pi}{2} \frac{0}{\pi}$

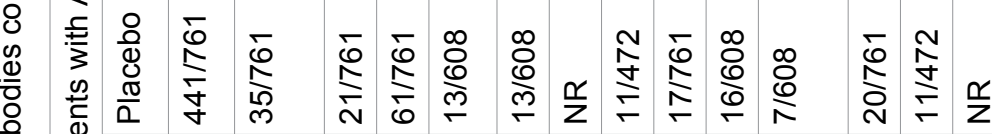

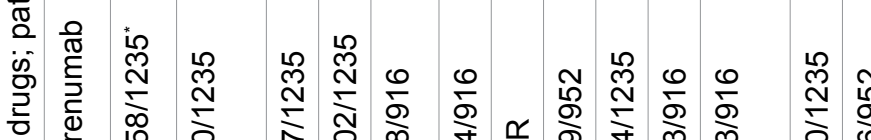
प

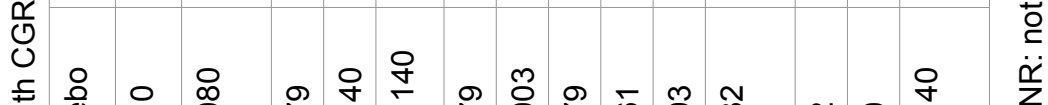

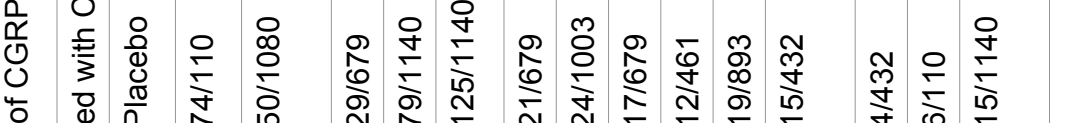

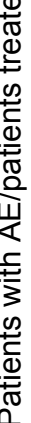

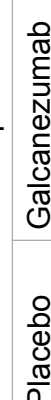
l.

N i

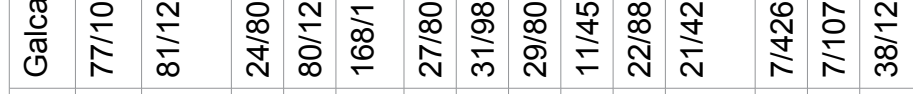

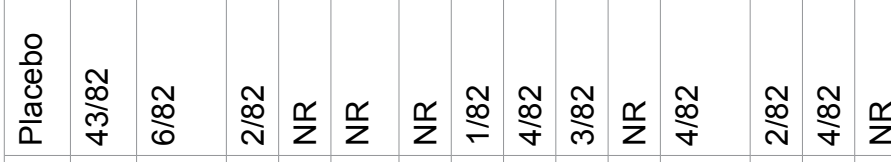

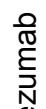

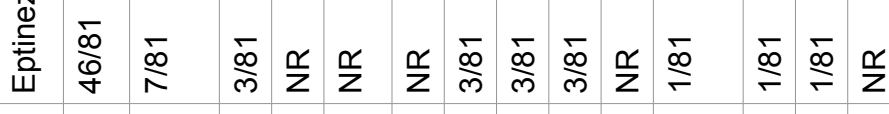
z
0 竞

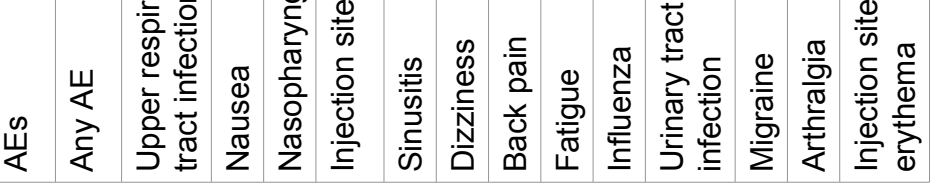


previous medical problems $[30,35,36]$. Injection site reactions were consistently the most common adverse effect amongst all trial data. In addition, other common adverse effects included: Upper respiratory tract infection, sinusitis, nasopharyngitis, influenza, back pain, and fatigue [30,31,33-37]. The withdrawal rate from the studies and reasons for cessation were not significantly different between treatment and placebo groups [3338]. These studies have demonstrated the protective vasodilatory effect of CGRP on the cardiovascular system, is not altered by the monoclonal antibodies.

Many of the studies do not specifically examine how response to CGRP monoclonal antibodies varies based on gender. This is an important variable because migraine patients are more likely to be women [39]. The efficacy of the migraine treatment was not affected when tested in mostly female participants. Females comprised 85 percent of participants in a study that found a significant reduction in migraine days, when comparing the effects of Galcanezumab in both high and low frequency migraine patients [5]. Women may also have greater reliance upon the protective effects of CGRP when compared to males. Female sex steroids have been shown to modulate the vasodilatory effects of CGRP [40]. Therefore, studies that have high or entirely female participation represent research that is important to accurately assessing the safety profile of the target population. A study of 31 women compared placebo and Fremanezumab treatment and it found no significant difference in heart rate, blood pressure, and ECG parameters [28]. Research articles were analyzed for this specific population of interest. Numerous studies consisted of a high female participation. These studies demonstrated consistency in their lack of adverse cardiovascular outcomes [30-37]. Females consisted of anywhere from 77 to 87 percent of the populations studied in these trials. This may be extrapolated to represent a positive safety profile in the female population, following CGRP monoclonal antibody use.

Current studies have not demonstrated concern for cardiovascular side effects when blocking CGRP. A meta-analysis examined ten randomized, double-blind, placebo-controlled trials of the four CGRP monoclonal antibodies in adults, aged 16-65, with episodic migraine, to evaluate the safety and efficacy. When the CGRP monoclonal antibody treatments were compared to placebo, the study found no significant difference in withdrawal rates, withdrawal rates due to adverse effects, severe adverse effects, or any adverse effect. Table 1 lists the common adverse effects reported by all ten studies. As visualized in the table, none of the studies reported any cardiovascular side effects related to the treatment medication [41]. This study was a meta-analysis that included phase II and III trials, which are some of the most current data currently published on the CGRP monoclonal antibodies. The meta-analysis found no significant difference in the safety of the med- ications when compared to placebo. This demonstrates that current research supports the CGRP monoclonal antibodies as well-tolerated medications with few cardiovascular side effects.

\section{Discussion}

Understanding the cardiovascular risk profile of monoclonal antibodies for migraine is important for CGRP monoclonal antibodies to be consistently used in treatment. Previous descriptions of the side effect profiles of this medication class, have called for further long term assessment of adverse events. This review identifies the most recent phase II and III trials on the topic. Consistently, CGRP monoclonal antibodies have not shown a significant difference in adverse outcomes, cardiovascular or otherwise, when drug treatment groups are compared to placebo. Vital signs have not been significantly affected. Patients with prior cardiovascular conditions have also not shown a significant difference in outcome. Studies that demonstrate these results are important for the current understanding of the cardiovascular risk profile of CGRP monoclonal antibodies. Although patients with migraines are at an increased risk of cardiovascular and cerebrovascular disease, CGRP monoclonal antibodies have demonstrated efficacy with few safety concerns. Phase IV trials for CGRP monoclonal antibodies will continue to provide valuable information on the safety profile. CGRP monoclonal antibodies require further study in patients with major cardiovascular risk. Currently, no research has shown cardiovascular risk with the use of CGRP monoclonal antibodies but a further exploration into their long term viability is warranted.

\section{Acknowledgements}

I would like to acknowledge Deen $M$, Correnti $E$, Kamm K, Kelderman T, Papetti L, Rubio-Beltrán E, Vigneri S, Edvinsson L, Maassen Van Den Brink A and Springer Nature for the use of Figure 1 within the contents of this manuscript. No changes were made to this figure. A link to the Creative Commons license is: http://creativecommons.org/licenses/by/4.0/.

\section{Additional acknowledgments}

Kumar A, Potts JD, DiPette DJ and Frontiers Publishing for the use of Figure 2 in text

Walter S, Alibhoy A, Escandon R, Bigal ME and Taylor and Francis Online for the use of Figure 3 in text. The Journal's website: www.tandfonline.com.

Ashina M, Goadsby PJ, Reuter U, Silberstein S, Dodick D, Rippon GA, Klatt J, Xue F, Chia V, Zhang F, Cheng S, Mikol DD and Sage Publishing for the use of Figure 4 in text.

Depre C, Antalik L, Starling A, Koren M, Eisele O, Lenz RA, Mikol DD and Wiley Online Library for the use of Figure 5 and Figure 6 in text. 
Xu, D., Chen, D., Zhu, L., Tan, G., Wang, H., Zhang, Y., \& Liu, L and Sage Publishing for the use of Table 1 in text.

\section{Financial Support}

There were no sources of financial support.

\section{Authors Contribution}

Each author contributed equally to the manuscript.

\section{References}

1. Durham PL (2006) Calcitonin gene-related peptide (CGRP) and migraine. Headache Suppl 1: S3-S8.

2. Goadsby PJ, Edvinsson L (1993) The trigeminovascular system and migraine: Studies characterizing cerebrovascular and neuropeptide changes seen in humans and cats. Ann Neurol 33: 48-56.

3. Edvinsson J, Warfvinge K, Krause DN, Blixt FW, Sheykhzade $M$, et al. (2019) C-fibers may modulate adjacent Aס-fibers through axon-axon CGRP signaling at nodes of Ranvier in the trigeminal system. The Journal of Headache and Pain 20: 105.

4. Deen M, Correnti E, Kamm K, Kelderman T, Papetti L, et al. (2017) Blocking CGRP in migraine patients - a review of pros and cons. J Headache Pain 18: 96.

5. Silberstein SD, Stauffer VL, Day KA, Lipsius S, Wilson MC, et al. (2019) Galcanezumab in episodic migraine: Subgroup analyses of efficacy by high versus low frequency of migraine headaches in phase 3 studies (EVOLVE-1 \& EVOLVE-2). The Journal of Headache and Pain 20: 75.

6. Detke HC, Goadsby PJ, Wang S, Friedman DI, Selzler KJ, et al. (2018) Galcanezumab in chronic migraine: The randomized, double-blind, placebo-controlled REGAIN study. Neurology 91: e2211-e2221.

7. Tepper S, Ashina M, Reuter U, Brandes JL, David Doležil, et al. (2017) Safety and efficacy of erenumab for preventive treatment of chronic migraine: a randomised, double-blind, placebo-controlled phase 2 trial. Lancet Neurol 16: 425434.

8. Goadsby PJ, Reuter U, Hallström Y, Broessner G, Jo H, et al. (2017) A Controlled Trial of Erenumab for Episodic Migraine. N Engl J Med 377: 2123-2132.

9. Silberstein SD, Aycardi E, Bigal ME, Yeung PP, Goadsby PJ, et al. (2017) Fremanezumab for the Preventative Treatment of Chronic Migraine. N Engl J Med 377: 2113-2122.

10. Akhtar A (2019) The Role of Anti-calcitonin Gene-related Peptide in Migraine and its Implication in Developing Countries: A Reasonable Option to Consider Despite Higher Cost. Cureus 11: e4796.

11. Tfelt-Hansen P, Vries PD, Saxena PR (2000) Triptans in Migraine: A comparative review of pharmacology, pharmacokinetics and efficacy. Drugs 60: 1259-1287.

12. Regan CP, Stump GL, Kane SA, Lynch JJ (2008) Calcitonin Gene-Related Peptide Receptor Antagonism Does Not Affect the Severity of Myocardial Ischemia during Atrial Pacing in Dogs with Coronary Artery Stenosis. J Pharmacol Exp Ther 328: 571-578.

13. Chaitman BR, Ho AP, Behm MO, Rowe JF, Palcza JS, et al. (2012) A Randomized, Placebo-Controlled Study of the Effects of Telcagepant on Exercise Time in Patients With Stable Angina. Clin Pharmacol Ther 91: 459-466.
14. Cui X-P, Ye J-X, Lin H, Mu JS, Lin M, et al. (2013) Efficacy, Safety, and Tolerability of Telcagepant in the Treatment of Acute Migraine: A meta-Analysis. Pain Practice 15: 124-131.

15. Kumar A, Potts JD, DiPette DJ (2019) Protective Role of a-Calcitonin Gene-Related Peptide in Cardiovascular Diseases. Front Physiol 10: 821.

16. Brain SD, Williams TJ, Tippins JR, Morris HR, Maclntyre I, et al. (1985) Calcitonin gene-related peptide is a potent vasodilator. Nature 313: 54-56.

17. Sueur S, Pesant M, Rochette L, Connat J-L (2005) Antiapoptotic effect of calcitonin gene- related peptide on oxidative stress-induced injury in $\mathrm{H} 9 \mathrm{c} 2$ cardiomyocytes via the RAMP1/CRLR complex. J Mol Cell Cardiol 39: 955-963.

18. Umoh NA, Walker RK, Millis RM, Al-Rubaiee M, Gangula PR, et al. (2014) Calcitonin Gene-Related Peptide Regulates Cardiomyocyte Survival through Regulation of Oxidative Stress by PI3K/Akt and MAPK Signaling Pathways. Ann Clin Exp Hypertens 2: 1007

19. Duan L, Lei H, Zhang Y, Wan B, Chang J, et al. (2015) Calcitonin Gene-Related Peptide Improves Hypoxia- Induced Inflammation and Apoptosis via Nitric Oxide in $\mathrm{H} 9 \mathrm{c} 2$ Cardiomyoblast Cells. Cardiology 133: 44-53.

20. Li J, Levick SP, Dipette DJ, Janicki JS, Supowit SC (2013) Alpha-calcitonin gene-related peptide is protective against pressure overload-induced heart failure. Regul Pept 185: 20-28.

21. Huang R, Karve A, Shah I, Bowers MC, DiPette DJ, et al. (2008) Deletion of the mouse a-calcitonin gene-related peptide gene increases the vulnerability of the heart to ischemia-reperfusion injury. American Journal of Physiology-Heart and Circulatory Physiology 294: H1291-H1297.

22. Supowit SC, Ramana CV, Westlund KN, Dipette DJ (1993) Calcitonin gene-related peptide gene expression in the spontaneously hypertensive rat. Hypertension 21 (6_pt_2): 1010-1014.

23. Gangula PRR, Zhao H, Supowit SC, Wimalawansa SJ, Dipette DJ, et al. (2000) Increased Blood Pressure in a-Calcitonin Gene-Related Peptide/Calcitonin Gene Knockout Mice. Hypertension 35: 470-475.

24. Aubdool AA, Thakore $P$, Argunhan F, Smillie SJ, Schnelle M, et al. (2017) A Novel a-Calcitonin Gene-Related Peptide Analogue Protects Against End-Organ Damage in Experimental Hypertension, Cardiac Hypertrophy, and Heart Failure. Circulation 136: 367-383.

25. Favoni V, Giani L, Al-Hassany L, Asioli GM, Butera C, et al. (2019) European Headache Federation School of Advanced Studies (EHF-SAS). CGRP and migraine from a cardiovascular point of view: what do we expect from blocking CGRP? J Headache Pain 20: 27.

26. Mahmoud AN, Mentias A, Elgendy AY, Qazi A, Barakat AF, et al. (2018) Migraine and the risk of cardiovascular and cerebrovascular events: A meta-analysis of 16 cohort studies including 1152407 subjects. BMJ Open 8: e020498.

27. Walter S, Alibhoy A, Escandon R, Bigal ME (2014) Evaluation of cardiovascular parameters in cynomolgus monkeys following IV administration of LBR-101, a monoclonal antibody against calcitonin gene-related peptide. MAbs 6 : 871-878.

28. Bigal ME, Walter S, Bronson M, Alibhoy A, Escandon R, et al. (2014) Cardiovascular and hemodynamic parameters in women following prolonged CGRP inhibition using LBR101, a monoclonal antibody against CGRP. Cephalalgia 34: 968-976. 
29. Depre C, Antalik L, Starling A, Koren M, Eisele O, et al. (2018) A Randomized, Double-Blind, Placebo-Controlled Study to Evaluate the Effect of Erenumab on Exercise Time During a Treadmill Test in Patients With Stable Angina. Headache 58: 715-723.

30. Ashina M, Goadsby PJ, Reuter U, Silberstein S, Dodick D, et al. (2019) Long-term safety and tolerability of erenumab: Three-plus year results from a five-year open-label extension study in episodic migraine. Cephalalgia 39: 1455-1464.

31. Sun H, Dodick DW, Silberstein S, Goadsby PJ, Reuter U, et al. (2016) Safety and efficacy of AMG 334 for prevention of episodic migraine: A randomised, double-blind, placebo-controlled, phase 2 trial. The Lancet Neurology 15: 382-390.

32. Dodick DW, Goadsby PJ, Spierings ELH, Scherer JC, Sweeney SP, et al. (2014) Safety and efficacy of LY2951742, a monoclonal antibody to calcitonin gene-related peptide, for the prevention of migraine: a phase 2 , randomised, double-blind, placebo-controlled study. The Lancet Neurology 13: 885-892.

33. Ferrari MD, Diener HC, Ning X, Galic M, Cohen JM, et al. (2019) Fremanezumab versus placebo for migraine prevention in patients with documented failure to up to four migraine preventive medication classes (FOCUS): A randomised, double-blind, placebo-controlled, phase $3 \mathrm{~b}$ trial. The Lancet 394: 1030-1040.

34. Silberstein SD, Mcallister P, Ning X, Faulhaber N, Lang N, et al. (2019) Safety and Tolerability of Fremanezumab for the Prevention of Migraine: A Pooled Analysis of Phases $2 b$ and 3 Clinical Trials. Headache 59: 880-890.
35. Skljarevski V, Matharu M, Millen BA, Ossipov MH, Kim BK, et al. (2018) Efficacy and safety of galcanezumab for the prevention of episodic migraine: Results of the EVOLVE-2 Phase 3 randomized controlled clinical trial. Cephalalgia 38: 1442-1454.

36. Dodick DW, Goadsby PJ, Silberstein SD, Lipton RB, Olesen J, et al. (2014) Safety and efficacy of ALD403, an antibody to calcitonin gene-related peptide, for the prevention of frequent episodic migraine: a randomised, double-blind, placebo-controlled, exploratory phase 2 trial. The Lancet Neurology 13: 1100-1107.

37. Dodick DW, Silberstein SD, Bigal ME, Yeung PP, Goadsby PJ, et al. (2018) Effect of Fremanezumab Compared With Placebo for Prevention of Episodic Migraine: A Randomized Clinical Trial. JAMA 319: 1999-2008.

38. Lionetto L, Cipolla F, Guglielmetti M, Martelletti P (2019) Fremanezumab for the prevention of chronic and episodic migraine. Drugs of Today 55: 265

39. Edvinsson L (2019) Role of CGRP in Migraine. Handb Exp Pharmacol 255: 121-130.

40. Gangula PRR, Wimalawansa SJ, Yallampalli C (2002) Sex Steroid Hormones Enhance Hypotensive Effects of Calcitonin Gene-Related Peptide in Aged Female Rats. Biol Reprod 67: 1881-1887.

41. Xu D, Chen D, Zhu L-N, Tan G, Wang HJ, et al. (2019) Safety and tolerability of calcitonin-gene-related peptide binding monoclonal antibodies for the prevention of episodic migraine - a meta-analysis of randomized controlled trials. Cephalalgia 39: 1164-1179. 